\title{
Role of Solanum dulcamara L. in Potato Late Blight Epidemiology
}

\author{
Tomek M. Golas • Gerard M. van der Weerden • \\ Ronald G. van den Berg • Celestina Mariani • \\ J. J. H. M. Allefs
}

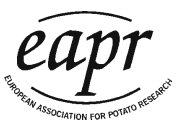

Received: 24 September 2009 /Accepted: 18 April $2010 /$

Published online: 7 May 2010

(C) The Author(s) 2010. This article is published with open access at Springerlink.com

\begin{abstract}
Four sites with naturally growing Solanum dulcamara were surveyed during 2006 and 2007 for the presence of late blight. Despite 2 years of observations, no late blight was detected among natural populations of bittersweet. Nevertheless, repeated infections occurred on few $S$. dulcamara plants from a collection growing in a botanical garden in the same years. These plants were used to investigate the possibility of survival of the inoculum between seasons. In the respective years, a set of 21 and $52 \mathrm{~S}$. dulcamara accessions inoculated with Phytophthora infestans under field conditions resulted in a wide range of responses to the disease. More susceptible reactions were found among genotypes collected at greater distance from commercial potato fields indicating the possibility of genetic selection caused by $P$. infestans. However, both scarceness of natural infections and no overwintering, suggest that bittersweet may not play a role in late blight epidemiology.
\end{abstract}

T. M. Golas $\cdot$ C. Mariani

Institute for Water and Wetlands Research, Department of Experimental Botany,

Radboud University Nijmegen, Heyendaalseweg 135, 6525 AJ Nijmegen, The Netherlands

G. M. van der Weerden

Institute of Water and Wetlands Research, Experimental Garden and Genebank,

Radboud University Nijmegen, Toernooiveld 11, 6525 ED Nijmegen, The Netherlands

R. G. van den Berg

Biosystematics Group, Wageningen University, Gen. Foulkesweg 37, 6703 BL Wageningen,

The Netherlands

J. J. H. M. Allefs

Agrico Research, B.V. Burchtweg 17, 8314 PP Bant, The Netherlands

T. M. Golas $(\bowtie) \cdot$ R. G. van den Berg $•$ C. Mariani $\cdot$ J. J. H. M. Allefs

Centre for BioSystems Genomics (CBSG), P.O. Box 98, 6700 AB Wageningen, The Netherlands

e-mail: t.golas@science.ru.nl 
Keywords Phytophthora infestans $\cdot$ Potato epidemiology ·

Solanum dulcamara (bittersweet)

\section{Introduction}

The oomycete Phytophthora infestans (Mont.) de Bary is the most important disease of the cultivated potato (Solanum tuberosum L.; Fry 2008). To limit the chance for disease onset, management strategies in potato production rely mainly on using certified seed material and reduction of the sources of primary infections. This is done by covering potato dumps and destroying volunteer plants that may emerge from tubers surviving the winter period and that may carry inoculum from the previous cropping season. Further, frequent preventive spraying with fungicides, between 10 and 16 times per season in The Netherlands, is a requirement in the disease management. $P$. infestans is able to infect other solanaceous species present in nature. An early observation of natural infection by $P$. infestans of weedy Solanaceae in Europe was described by Hirst and Steadman (1960) with late blight occurring on Solanum nigrum L. and Solanum dulcamara L. More recent reports of infections from 1999 and 2001 are described by Flier et al. (2003a) and Deahl et al. (2004). Besides S. nigrum and S. dulcamara, four other species of Solanaceae, Solanum physalifolium Rusby, Solanum sarrachoides Mill., Solanum villosum Lam., and Solanum sisymbriifolium Lam. (the latter species used as a trap crop for sanitation of fields infected by potato cyst nematode), are present in Europe and USA and may serve as an alternative host (Andersson and Johansson 2003; Flier et al. 2003a; Olanya et al. 2005). Other cultivated Solanaceae such as tomato (Solanum lycopersicum Mill.), to some extent petunia (Petunia hybrida Vilm.; Deahl and Fravel 2003) and Solanum scabrum Mill. (Fontem et al. 2004), are also found infected by $P$. infestans. To prove the role of wild solanaceous species as an alternative host for late blight, it has been also attempted to confirm pathogenicity of P. infestans on wild hosts under laboratory conditions (Peterson 1947; Platt 1999; Cooke et al. 2002; Andersson and Johansson 2003; Deahl et al. 2004; Fontem et al. 2004; Olanya et al. 2005; Lebecka 2007). In these reports, however, the role of the plants as a source of primary infections or as main source of late blight presence was not fully confirmed. In The Netherlands, two solanaceous species are very common: $S$. nigrum that grows as an annual weed on arable land and S. dulcamara, a perennial plant present abundantly along canals, in wetlands, irrigation ditches, and less frequent in dune areas along the North Sea coast. S. dulcamara, commonly named bittersweet or climbing nightshade, has been known for a long time as a host for P. infestans under natural conditions (de Bary 1876; Cooke et al. 2002; Flier et al. 2003a). However, the potential role of bittersweet as reservoir of inoculum from which epidemics in commercial potato production might begin has not been proven thus far. To investigate this possibility, we carried out a survey to estimate frequency of natural late blight infections occurring on S. dulcamara. Furthermore, to investigate the role of $S$. dulcamara as a host for $P$. infestans, accessions collected from a range of geographically different areas were tested for their resistance under experimental field conditions. Moreover, during our study, severe infections occurred on some accessions of bittersweet planted at Radboud University Experimental Garden and Genebank and 
allowed us to monitor the survival of $P$. infestans on $S$. dulcamara over the winter period.

\section{Materials and Methods}

\section{Monitoring of Late Blight on S. dulcamara}

Five sites were selected as monitoring spots: four with naturally occurring $S$. dulcamara in its habitat (Figs. 1a (sites 1, 2, 3, and 4) and 2a) and one in an artificial setting where a collection was maintained as perennials (Table 1 and Fig. 1a, site 5). About 50 plants growing in dense vegetation were monitored (sites 1 and 2), together with few individuals separated by 200 to $300 \mathrm{~m}$ (sites 3 and 4). Monitoring started on 1 May and finished on 30 September 2006 and 2007, and was carried out every 2 weeks. During the observation period, leaves that potentially showed late blight symptoms were collected, examined under the binocular, and then inserted in watersoaked florist foam, placed in a box with a transparent lid at $100 \%$ humidity, and incubated for 1 week in a climate chamber $\left(18{ }^{\circ} \mathrm{C} ; 16 \mathrm{~h}\right.$ day $/ 8 \mathrm{~h}$ night $)$ to promote disease development. Daily reports of weather conditions and late blight detections in The Netherlands during the investigated period were obtained from Dacom Plant Service (The Netherlands; Fig. 1).

\section{Natural Variation for Resistance to Late Blight in Accessions of S. dulcamara}

Seeds of $56 S$. dulcamara accessions from the Solanaceae collection of the Radboud University Experimental Garden and Genebank and seeds collected in 2005 and 2006 from $S$. dulcamara plants growing in their natural habitats were used (Table 1). Accession 94001 (Table 1 and Fig. 2b), obtained in the course of another study (Golas et al. 2010), was used as a susceptible control. Additionally, cuttings were collected from a monitored plant growing in direct vicinity of potato fields (code, 206065; Fig. 1a, site 3). All accession numbers were abbreviated, e.g., accession number 944750001 is abbreviated to 94001 or A64750009 to A6009, and their passport data can be found at http://www.bgard.science.ru.nl/solanaceae/. All plant material was cultivated in the greenhouse at the Radboud University Experimental Garden and Genebank under long day conditions (16 h day/8 h night). Supplementary light was given by using high-pressure sodium lamps (SON-T, $600 \mathrm{~W})$. Plants were grown in 1-1 pots filled with a standard soil mixture (Lentse Potgrond no. 4). Regularly, the plants were fertilized with $2 \mathrm{~g}^{-1}$ of Kristallon Blauw, NPK 19:6:30 (Yara Benelux B.V., Vlaardingen). Approximately 8-week-old plants, one plant per accession, were chosen randomly for vegetative propagation. From the selected plants, single-node cuttings were taken, placed in wet soil, and covered with plastic foil to increase humidity for a period of 4 days. A minimum of nine rooted cuttings was obtained per individual by the second half of May 2006 and 2007. On 22 June 2006 and 2007, S. dulcamara plants were planted on an experimental field near Marknesse (The Netherlands; Fig. 1a, site 6), where potatobreeding material was tested for late blight resistance. The experiment was designed in three randomized blocks, each block containing a plot of three plants. In the last 

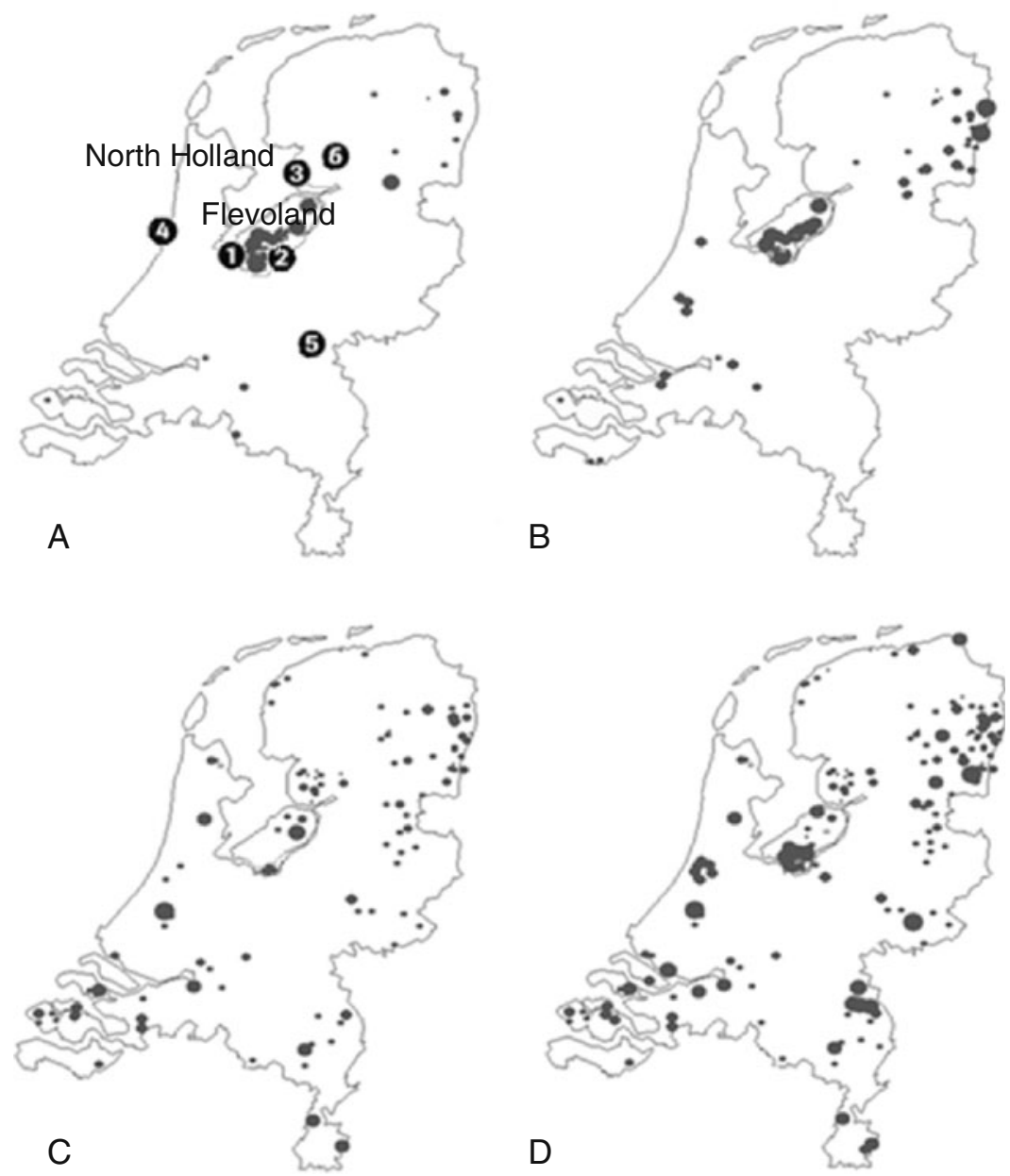

2007

Fig. 1 Map of The Netherlands with spots indicating late blight attacks reported on potato. The size of the dot indicates the severity of each outbreak. a Shows where late blight was reported on 20 August 2006. b Shows where late blight was reported on 5 September 2006. c Shows late blight appearance on 25 June 2007. d Shows late blight reported on 1 August 2007. Sites of Solanum dulcamara observed for natural infections during 2006 and 2007 season are marked on a: site 1, vicinity of Almerehout (bank of Gooimeer); site 2, Zeewolde (bank of Veluwemeer); site 3, South of Nagele (bank of Zwarte meer); site 4, Castricum aan Zee (dune area); site 5, Radboud University Experimental Garden and Genebank; site 6, experimental field where $S$. dulcamara accessions were artificially inoculated with Phytophthora infestans. The main concentration of organic potato production is located in the provinces of Flevoland and North Holland

week of July, spray inoculation was carried out with a suspension of $P$. infestans [complex A2 isolate IPO 82001, race 1, 2, 3, 4, 5, 6, 7, 10, and 11 (Flier et al. 2003b)]. Observations of disease development started 3 weeks after inoculation and lasted until the last week of September. Four types of observations were made, namely, presence of healthy tissue, severity of leaf drop, sporulation intensity, and a total impression of plant fitness. A value for field resistance of a given individual was 


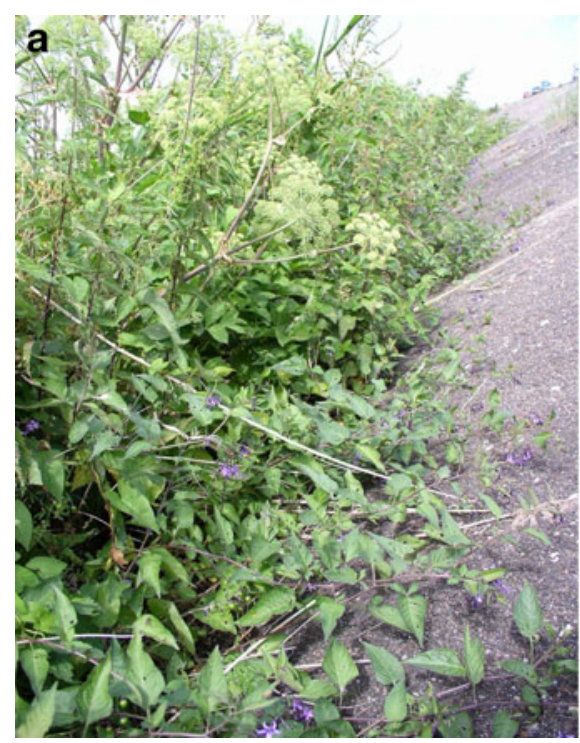

b

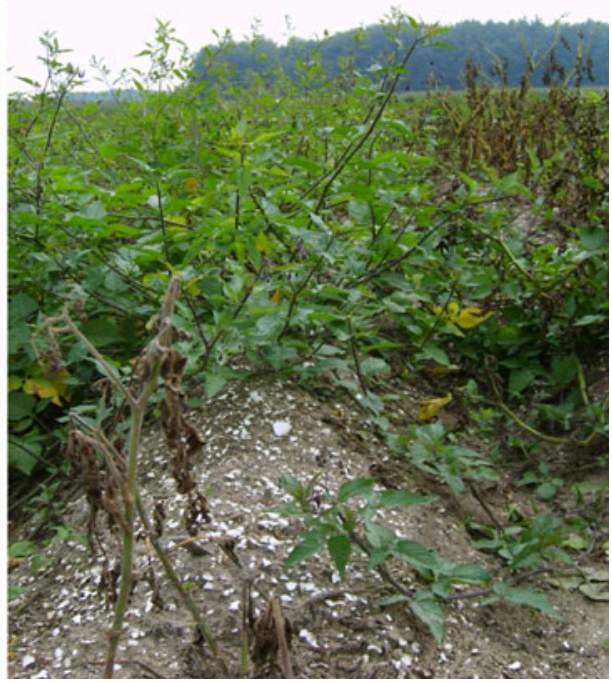

Fig. 2 a A stretch of Solanum dulcamara plants growing between Angelica sylvestris L., Phragmites australis (Cav.) Trin. ex Steud, and Urtica dioica L. along the dam of the Gooimeer (Fig. 1a, site 1). b A susceptible control (94001, in front) and a resistant genotype (206065, in the back) in the experimental field trial at Marknesse (Fig. 1a, site 6)

calculated as the average score for all observations made during a testing season on a scale of 3 to 9, as described by Golas et al. (2010), where 3 indicates a susceptible/ unhealthy plant and 9 a resistant/healthy plant.

\section{Overwintering Potential of $P$. infestans on $S$. dulcamara Plants}

To maintain the collection of $S$. dulcamara, five plants of each of the 56 accessions (Table 1) were planted in the Radboud University Experimental Garden and Genebank in May 2006 and maintained throughout the year 2007. To confirm the presence of $P$. infestans on four individuals, each corresponding to one accession naturally infected by late blight in 2006 and 2007 (Table 2), binocular examinations for the presence of sporangia were carried out. Additionally, detached leaf assays were performed as described by Vleeshouwers et al. (1999) to confirm that isolates collected from diseased $S$. dulcamara plants were pathogenic on cultivated potato. Sporangial suspensions of $P$. infestans were obtained by rinsing leaves of infected $S$. dulcamara plants in water. Inoculation was carried out by applying two $10-\mu 1$ drops of the suspension on the abaxial leaf side of detached leaves of the susceptible cultivar Bintje. Five replicates of each zoospore suspension were tested. Pathogenicity of isolates was estimated after 7 days. In the first week of March 2007, selected plants were covered with a plastic tent to increase humidity and promote development of potentially overwintering $P$. infestans on $S$. dulcamara. Plants inside the tent were frequently sprayed with water. In March, after the start of the vegetation, leaves and stems of bittersweet plants were checked daily for late blight symptoms. 


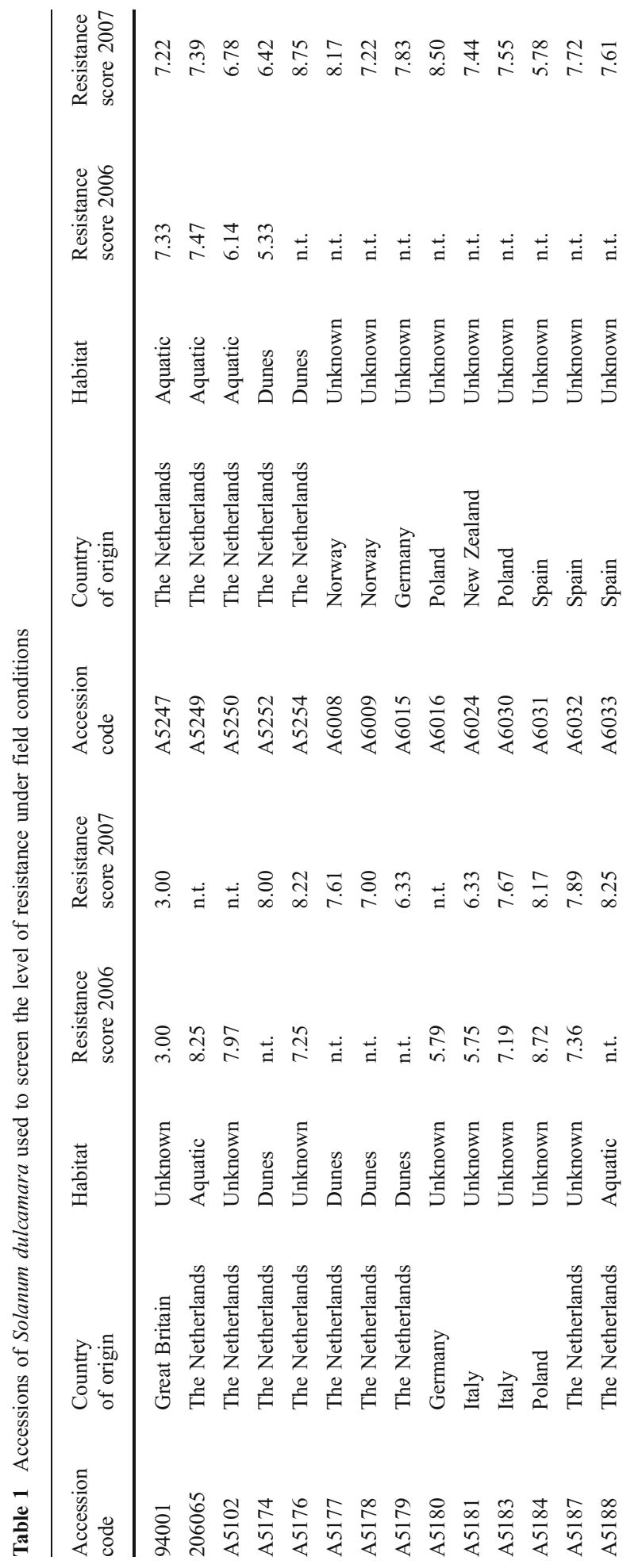




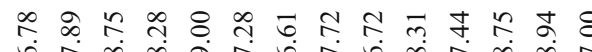

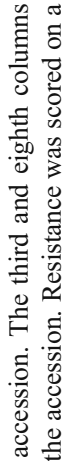

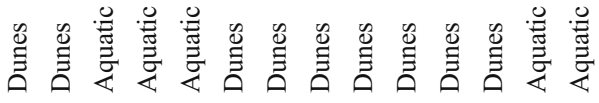

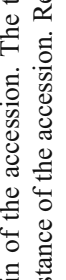

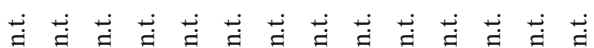

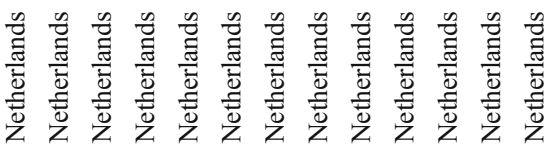

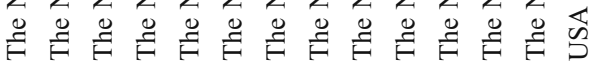

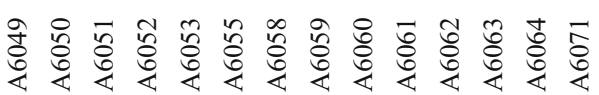

焉.

을 을

空它

竞岩

政

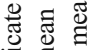

㱒

党客范

害

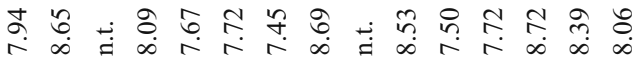

政

递志

㱐

政

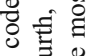

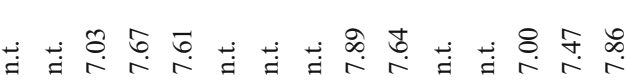

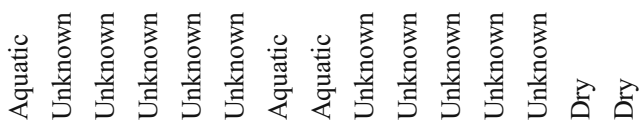

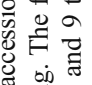

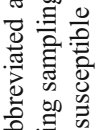

卷

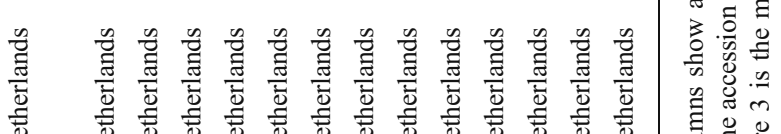

言害蓬

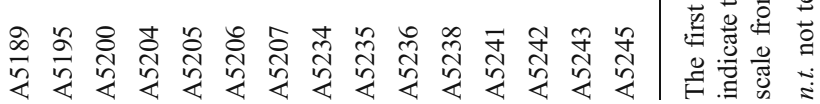


Table 2 Accessions of Solanum dulcamara infected by Phytophthora infestans in Radboud University Experimental Garden and Genebank

\begin{tabular}{lllll}
\hline $\begin{array}{l}\text { Accession } \\
\text { code }\end{array}$ & $\begin{array}{l}\text { Field resistance } \\
2006\end{array}$ & $\begin{array}{l}\text { Degree of natural } \\
\text { infection in 2006 }\end{array}$ & $\begin{array}{l}\text { Field resistance } \\
2007\end{array}$ & $\begin{array}{l}\text { Degree of natural } \\
\text { infection in } 2007\end{array}$ \\
\hline A5250 & 6.14 & Lesions no sporulation/regrowth & 6.78 & Not infected \\
A5252 & 5.33 & Sporulation/regrowth & 6.42 & Sporulation/regrowth \\
A5179 & n.t. & Sporulation/regrowth & 6.33 & Lesions no sporulation \\
94001 & 3.00 & Sporulation/no regrowth & 3.00 & Sporulation/no regrowth \\
\hline
\end{tabular}

The first column shows an abbreviated accession code. The second column shows an average score of the field resistance in 2006, where 3 is the most susceptible and 9 the most resistant response. The third column describes symptoms of natural late blight infection in 2006. The fourth column shows a mean score of the field resistance in 2007. The fifth column describes symptoms of natural late infection in 2007 n.t. not tested

\section{Results}

\section{Monitoring of Late Blight on S. dulcamara}

Visual examinations were carried out in regions where $S$. dulcamara is growing in high density, close to commercially grown potato crops (Fig. 1a and 2a) and in dunes on the shores of the North Sea, near Castricum aan Zee (Fig. 1a). In The Netherlands, a hot and dry period with little risk for late blight outbreak occurred in May, June, July, and second half of September of 2006. In August, the weather shifted to mild and rainy, conditions more favourable for late blight development. At the beginning of August, disease outbreaks on monitored cultivated potatoes were reported in many potato fields across the northern part of the country, and on 20 August, 38 outbreaks (Fig. 1a) of late blight infection were reported across the country, which number finally increased to 93 outbreaks on 5 September (Fig. 1b) and later started to decrease. Throughout the entire period, S. dulcamara growing in the four natural environments remained free from the disease. Approximately 100 leaf samples from four sites carrying lesions resembled those of $P$. infestans were collected. Upon further incubation, they did not confirm the presence of $P$. infestans.

During the last week of August 2006, four out of 56 S. dulcamara accessions previously planted in Radboud University Experimental Garden and Genebank were found to be naturally infected by late blight (Table 2). The first infections appeared when late blight was well established on cultivated potato (between 20.08 and 5.09), and in some regions of The Netherlands, the aerial concentration of spores was estimated as high. This was 4 weeks after a period of optimal weather conditions for late blight infection had started and 3 weeks after the first reports of late blight epidemics in commercial farming. When disease pressure lowered, bittersweet plants started to recover throughout the second part of September and October. Some berries, although formed, did not ripen before the end of the growing season. Initial disease symptoms on bittersweet plants were found on green and healthy leaves with various severity. Lesions without sporulation, clearly sporulating lesions, and 
collapsed plants were observed (Table 2). The presence of $P$. infestans on these plants was confirmed visually by using an optical binocular and by the detached leaf assay in which a suspension of zoospores rinsed from sporulating leaves of bittersweet was applied on the leaves of susceptible cultivar Bintje. In all cases, after 7 days, clear and typical sporulation was observed. In some cases, detection of $P$. infestans in $S$. dulcamara was done using quantitative real-time polymerase chain reaction (TaqMan; data not shown).

Throughout the entire 2007 growing season, visual examinations were continued. In May, the first half of June, and in September, the disease pressure was relatively low due to warm and dry weather conditions. Optimal weather conditions for late blight development prevailed in the second half of June and in July and provoked outbreaks of the disease (Fig. 1c, d). During this season, late blight pressure on cultivated potato and hence on wild solanaceous species was significantly higher than in 2006 with 131 reported late blight outbreaks on the monitored sites already on 25 June (Fig. 1c). The number of outbreaks reached a maximum number of 212 on 1 August (Fig. 1d). Notwithstanding the early start of the epidemics, the higher number of late blight outbreaks, and the overall longer period of favourable weather conditions than in 2006, again leaves of bittersweet with symptoms resembling late blight, upon further incubation, did not sporulate under laboratory conditions. Thus, infections were not detected on $S$. dulcamara in its natural habitat.

In 2007, at Radboud University and Experimental Garden and Genebank, three out of four accessions infected in 2006 were attacked again. Only the most resistant accession from the previously infected group showed no disease symptoms (A5250; Table 2). The first infections of $S$. dulcamara appeared on 5 July 2007, and more infections appeared on already infected plants until approximately 1 August. After that day, we did not find late blight on S. dulcamara anymore, and except for plants of accession 94001, all plants recovered. Some small berries were formed on recovered shoots, but less than on healthy plants. Despite the higher disease pressure in 2007 compared to 2006 (Fig. 1), the severity of infections in the Radboud University Experimental Garden and Genebank was relatively weaker. Similar to the previous season, disease outbreaks started 3 weeks after epidemics in commercial potato farming had been recorded.

\section{Natural Variation for Resistance to Late Blight in Accessions of S. dulcamara}

To study the level of resistance that is present in natural bittersweet populations, a set of 21 and 52 accessions was screened for resistance to late blight under field conditions in 2006 and 2007, respectively (Table 1). A majority of the accessions tested in 2006 showed a high level of resistance against late blight, but susceptible reactions were present as well. In total, 16 accessions showed a high level of field resistance with scores of 7 or higher, whereas the remaining five accessions scored less than 7. From the set of accessions collected outside The Netherlands, the Polish accession A5184 with the resistance score 8.72 and the Italian accession A5183 with the resistance score 7.19 were the most resistant genotypes tested in 2006. The remaining accessions from Germany (A5180A) and Italy (A5181) were found to be susceptible to the pathogen with the resistance scores 5.79 and 5.75, respectively. In general, the Dutch accessions were very resistant to the pathogen. Clone 206065 
(Fig. 2b) was the most resistant genotype present in the Dutch collection with a resistance score of 8.25. Other resistant accessions were representing various regions and habitats throughout The Netherlands. The most susceptible Dutch accession A5252 with the resistance score 5.33 had been collected in the dune area of the western part of The Netherlands near Castricum aan Zee. A second rather susceptible accession A5250 (resistance score, 6.14) was collected in Schardam (province of North Holland). Except the susceptible control 94001, which scored a value of 3.00 (lowest score of all genotypes) and was killed by the pathogen, all diseased plants recovered by re-sprouting when disease pressure lowered in the second half of September. Differences in the susceptibility to late blight among accessions could not be directly ascribed to geographical origin or the habitat in which a particular accession had been collected (Table 1). The group of resistant genotypes represented various collection sites such as the dunes along the North Sea, the provinces of North Holland, Flevoland, and eastern parts of The Netherlands. However, the most susceptible accession was collected in a dune area where potato cultivation is not present and disease pressure is lower, whereas the most resistant plant (code, 206065) was growing in direct vicinity of a potato field in an area of intense potato production. In 2007, 52 accessions were tested (Table 1). As in 2006, accession 94001 was included as a susceptible control, and again in 2007, this plant showed the lowest level of resistance with an average disease score of 3.00. Similar to the 2006 field trial, the majority of the accessions exhibited a high level of resistance to P. infestans. Forty-three accessions scored a resistance level at 7.00 or higher. A low level of resistance was observed in nine accessions with a disease score below 7.00. The 12 accessions collected outside The Netherlands had disease scores of 7.00 or higher, and three scored lower than 7.00. The most resistant accessions of foreign origin were from Italy (A5195) and Poland (A6016) with resistance scores 8.50 and 8.65, respectively. An Italian accession A5181 again was classified as susceptible to late blight. A second susceptible accession A6031 was from Spain with a disease score of 5.78. Out of 37 Dutch accessions, 31 were resistant to late blight. Within that group, six accessions had the highest resistance level observed during the 2 years of experimentation. The six most susceptible accessions were originated from the Dutch collection. The lowest level of resistance was again observed among genotypes collected in dune areas where five out of these six most susceptible accessions had been collected. The sixth accession, A5250, was from Schardam (North Holland) and had been scored as susceptible in 2007 as well. To evaluate the possible differences in mean resistance values as a result of seasonal variation, 16 accessions that had been screened in 2006 were also tested in 2007 (Table 1). Results showed a high and positive linear correlation $(r=0.92)$ indicating that field trials were reproducible over both seasons.

\section{Overwintering Potential of P. infestans on S. dulcamara Plants}

Three out of four individuals (except 94001 that did not survive 2006 infection) naturally infected by late blight in 2006 at Radboud University Experimental Garden and Genebank were used to test whether $P$. infestans can survive winter on bittersweet plants (Table 2). Sprouts gradually appearing between March and end of April of 2007 were every day visually evaluated for disease symptoms. In total, three 
individuals produced 31 shoots, some of which originated from the roots as they were emerging through the soil. Despite prolonged humid conditions, required for the life cycle of $P$. infestans and for virulence, after continuous observations, we could not find unhealthy shoots.

\section{Discussion}

In the present study, all S. dulcamara plants growing in their natural environment along water channels, in vicinity of organically grown potatoes, or in dunes were found to be resistant to late blight. Despite collection of many leaves with symptoms resembling late blight, we could not confirm the presence of the pathogen on any of them. In the study of Cooke et al. (2002), repeated natural infections were found on a single plant growing less than $100 \mathrm{~m}$ from the infected experimental plot of potato. In our case, two stretches of $S$. dulcamara (Fig. 1, sites 1 and 2), each containing at least 50 plants, were growing at a similar distance from organically cultivated potato crops, but representatives of these proved to be highly resistant. Until now, there are only few reports describing blighted bittersweet plants in nature (de Bary 1876; Flier et al. 2003a). The rareness of such reports and the lack of positive results in this study indicate that susceptibility in this species is rather unique, and that the impact of bittersweet on overall late blight epidemiology must be minimal. Similar conclusions were drawn by Flier et al. (2003a, b), who stated that the low frequency of natural infections observed cannot significantly contribute to overall late blight epidemiology. It is highly probable that very susceptible plants are eliminated at an early stage of development (or even at seedling stage), as we have noticed for the susceptible S. dulcamara plants (accession 94001) that were infected in the Radboud University Experimental Garden and Genebank. Apparently, most $S$. dulcamara plants are capable of surviving the epidemics that occur in potato. A similar situation was described for Mexican species of Solanum demissum and Solanum verrucosum by Rivera-Peña (1990a). However, infection severely impairs fitness and reproduction of plants that are relatively susceptible, lowering their share in the population. It is plausible to attribute this process merely to the frequently observed late blight lesions on young stems that cause these to collapse, thus obstructing the formation of inflorescence and berries. Although nodal regrowth later in the season occurs, this retardation prevents susceptible plants from forming a good number of berries, as compared to more resistant plants. Hence, their contribution to the offspring generation is anticipated to be significantly lower. The infections observed at the Radboud University Experimental Garden and Genebank confirmed that $S$. dulcamara, like the cultivated potato, is a host of late blight. Infections on bittersweet appeared when late blight was well established on cultivated potato and the disease pressure was high. This situation was observed both during the 2006 and the 2007 seasons when infections by $P$. infestans were appearing on $S$. dulcamara approximately 3 weeks after the first infections were reported in commercial potato farming. As soon as the disease pressure lowered, moderately susceptible plants recovered. Similarly to our observations, Rivera-Peña (1990b) in Mexico observed late blight infections 
earlier on susceptible cultivars and then on wild Solanum species. Grünwald et al. (2001) also observed that epidemics on wild Solanum rarely occur before the end of August or beginning of September. This was the time when late blight had already well established in commercial cultivation. In North America, Deahl et al. (2004, 2006) and Olanya et al. (2005) also noticed blighted wild Solanum species in the vicinity of already heavily blighted potato fields. We observed a remarkable dissimilarity in severity of attacks in 2006 and 2007 at Radboud University Experimental Garden and Genebank. Despite higher disease pressure in The Netherlands in 2007 (Fig. 1), accessions suffered less than the same accessions during 2006. This difference could be caused by seasonal changes in P. infestans population structure and virulence pattern. The prevailing population of $P$. infestans in 2007 might have had a different virulence spectrum than in 2006 or could have been less adapted to bittersweet. It is also possible that $P$. infestans, when migrating from its original host, potato, might not have been well adapted to a different host like $S$. dulcamara. This situation was described by Garry et al. (2005) who observed that the oomycete was more aggressive on its original host S. tuberosum than on Solanum caripense Dunal. Results from the field experiments point in the direction that the regions where $S$. dulcamara accessions were collected might have some influence on the observed frequency of susceptible and resistant individuals in the bittersweet population. We have observed more susceptible genotypes in the part of the population that was collected in the dune area, especially in 2007. By contrast, the most resistant plant (code, 206065) was collected in direct vicinity to a potato production area further supporting this statement. However, since resistant and susceptible reactions were both present among accessions from dunes and potato-producing areas, respectively, the resistance level of $S$. dulcamara plants is not strictly region specific. Based on our observations, $S$. dulcamara cannot support living $P$. infestans throughout the winter nor be responsible for starting the infections early in the season. Despite thorough observations of plants that had been naturally infected in the previous season, we did not see any signs of late blight on fresh bittersweet sprouts emerging in the spring on these plants under conditions that favour P. infestans.

Despite sanitary precautions taken by farmers, late blight threatens potato cultivation each season and, therefore, the role of weedy Solanaceae in initiating epidemics has been questioned frequently. We conclude that $S$. dulcamara infections in nature are at most scarce and hence not highly relevant in late blight epidemiology. The species seems also not to be reservoir for overwintering of the inoculum from the previous cropping season and does not seem to initiate epidemics that occur during the potato vegetation periods. However, it is clear that bittersweet is a good host and can suffer like cultivated potato from the attacks of the pathogen.

Acknowledgements The authors acknowledge CBSG for funding this project. Thanks also go the gardeners of Radboud University Experimental Garden and Genebank for their help with maintenance of S. dulcamara plants.

Open Access This article is distributed under the terms of the Creative Commons Attribution Noncommercial License which permits any noncommercial use, distribution, and reproduction in any medium, provided the original author(s) and source are credited. 


\section{References}

Andersson B, Johansson M (2003) First report of Solanum physalifolium as a host plant for Phytophthora infestans in Sweden. Plant Dis 87:1538

Cooke LR, Carlisle DJ, Wilson DG, Deahl KL (2002) Natural occurrence of Phytophthora infestans on woody nightshade (Solanum dulcamara) in Ireland. Plant Pathol 51:392

de Bary A (1876) Researches into the nature of the potato fungus Phytophthora infestans. J Roy Agr Soc Engl 12:239-269

Deahl KL, Fravel DR (2003) Occurrence of leaf blight on petunia caused by Phytophthora infestans in Maryland. Plant Dis 87:1004

Deahl KL, Shaw DS, Cooke LR (2004) Natural occurrence of Phytophthora infestans on black nightshade (Solanum nigrum) in Wales. Plant Dis 88:771

Deahl KL, Jones RW, Perez FM, Shaw DS, Cooke LR (2006) Characterization of isolates of Phytophthora infestans from four solanaceous hosts growing in association with late blight-infected commercial potato crops. HortScience 41:1635-1639

Flier WG, Van den Bosch GBM, Turkensteen LJ (2003a) Epidemiological importance of Solanum sisymbriifolium, S. nigrum and $S$. dulcamara as alternative hosts for Phytophthora infestans. Plant Pathol 52:595-603

Flier WG, Van den Bosch GBM, Turkensteen LJ (2003b) Stability of partial resistance in potato cultivars exposed to aggressive strains of Phytophthora infestans. Plant Pathol 52:326-337

Fontem DA, Olanya OM, Njualem BF (2004) Reaction of certain solanaceous and astraceous plant species to inoculation with Phytophthora infestans in Cameroon. J Phytopathol 152:331-336

Fry W (2008) Phytophthora infestans: the plant (and $R$ gene) destroyer. Mol Plant Pathol 9:385-402

Garry G, Forbes GA, Salas A, Santa Cruz M, Perez WG, Nelson RJ (2005) Genetic diversity and host differentiation among isolates of Phytophthora infestans from cultivated potato and wild solanaceous hosts in Peru. Plant Pathol 54:740-748

Golas TM, Sikkema A, Gros J, Feron RMC, Van den Berg RG, Van der Weerden GM, Mariani C, Allefs JJHM (2010) Identification of a resistance gene Rpi-dlcl to Phytophthora infestans in European accessions of Solanum dulcamara. Theor Appl Genet 120:797-808

Grünwald NJ, Flier WG, Sturbaum AK, Garay-Serrano E, van den Bosch TBM, Smart CD, Matuszak JM, Lozoya-Saldana H, Turkensteen LJ, Fry WE (2001) Population structure of Phytophthora infestans in the Toluca valley region of Central Mexico. Phytopathol 91:882-890

Hirst JM, Steadman OJ (1960) The epidemiology of Phytophthora infestans. The source of infection. Ann App Biol 48:489-517

Lebecka R (2007) Host-pathogen interaction between Phytophthora infestans and Solanum nigrum, S. villosum and S. scabrum. Eur J Plant Pathol 120:233-340

Olanya OM, Lambert DH, Plant AB (2005) Occurrence and cross infection of Phytophthora infestans on hairy nightshade (Solanum sarrachoides) and potato (Solanum tuberosum) in Maine. Can J Plant Pathol 27:458-460

Peterson LC (1947) The overwintering of Phytophthora infestans (Mont.) de Bary under Long Island conditions. Amer Pot J 24:188-197

Platt HW (1999) Response of solanaceous cultivated plants and weed species to inoculation with A1 or A2 mating type strains of Phytophthora infestans. Can J Plant Pathol 21:301-307

Rivera-Peña A (1990a) Wild tuber-bearing species of Solanum and incidence of Phytophthora infestans (Mont.) de Bary on the western slopes of the volcano Nevado de Toluca. 2. Distribution of Phytophthora infestans. Pot Res 33:341-347

Rivera-Peña A (1990b) Wild tuber-bearing species of Solanum and incidence of Phytophthora infestans (Mont.) de Bary on western slopes of the volcano Nevado de Toluca. 3. Physiological races of Phytophthora infestans. Pot Res 33:349-355

Vleeshouwers VGAA, Van Dooijeweert W, Keizer LCP, Sijpkes L, Govers F, Colon LT (1999) A laboratory assay for Phytophthora infestans resistance in various Solanum species reflects the field situation. Eur J Plant Pathol 105:241-250 